\title{
UMA SKHOLÉ PARA PROFESSORES: O ESTUDO COMO DIMENSÃO CONSTITUTIVA DO OFÍCIO DE PROFESSOR
}

\author{
A skbole for teachers: the study as a constitutive dimension \\ of the teacher's work
}

Karen Christine RECHIA, Caroline Jaques CUBAS

Universidade Federal de Santa Catarina. Brasil.

krechia@gmail.com; caroljcubas@gmail.com

https://orcid.org/0000-0002-1399-9525; bttps://orcid.org/0000-0001-5411-6824

Fecha de recepción: 06/06/2019

Fecha de aceptación: 15/07/2019

Fecha de publicación en línea: 05/09/2019

RESUMO

A presente proposição reivindica o estudo como elemento constitutivo e basilar do ofício de professor. Neste texto, nos dedicaremos a pensá-lo a partir de atividades desenvolvidas no escopo da formação docente inicial, nossa área de atuação (uma, professora de um curso de licenciatura em uma universidade pública e a outra, professora de uma instituição escolar pública de ensino fundamental e médio). Tal atuação nos possibilita indicar, em um primeiro momento, certas incongruências no discurso acerca da profissionalização/ burocratização do professor. Neste sentido, destacamos que a formação docente inicial tem cada vez mais se fundamentado em uma lógica de aprendizagem, de desenvolvimento de competências e habilidades voltadas, na maioria das vezes, à garantia de inserção no mercado de trabalho e atuação profissional adaptada a lógicas produtivistas. Diante disto, nos propomos a pensar, no interior de uma noção de skholé-de um tempo livre e de um espaço público-, as possibilidades de estudo do ofício não somente em seus conteúdos específicos e metodologias, mas, especialmente, através de seus gestos, maneiras e modos de fazer. Por isso o foco não está num método docente, mas na ativação de uma experimentação desenvolvida através de observações, pensamentos e práticas 
que coloquem a escola -e por conseguinte a sala de aula-como matéria de estudo. Portanto o estágio, esta etapa fundamental da formação docente inicial, constitui-se em um tempo e espaço de atenção à escola. Tem por assunto o ofício do professor e por matéria os elementos que constituem este ofício. Para tanto, amparamo-nos particularmente nos escritos de Jan Masschelein e Marteen Simons sobre a noção de escolar e de Jorge Larrosa, sobre o ofício de professor.

Palavras-chave: estudo; ofício; skholé; formação de professores.

\section{ABSTRACT}

The present proposition claims the study as a constitutive and basic element of the teacher's work. In this text, we will think about it through activities developed within the scope of initial teacher training, our area of activity (one, teacher of a licentiate course at a public university and the other, teacher of elementary and high level at a public school). Such action allows us to indicate, at first, certain incongruities in the discourse about the professionalization / bureaucratization of the teacher. In this sense, we emphasize that the initial teachers training is increasingly based on a logic of learning and skills development, most of which are aimed at ensuring the insertion in the job market and professional performance adapted to productivist logics. In view of this, we propose to think within the notion of skhole - a free time and a public space - the possibilities of studying the craft not only in its specific contents and methodologies, but especially through its gestures and ways of doing. Therefore, the focus is not on a teaching method, but on the activation of an experimentation developed through observations, thoughts and practices that put the school - and consequently the classroom - as a subject of study. On that account, the practicum, this fundamental stage of initial teachers training, is a time and space of attention at the school. Its subject is the work of the teacher and its matter the elements that constitute this work. To that end, we particularly rely on the writings of Jan Masschelein and Marteen Simons on the notion of scholar and Jorge Larrosa on the work of teacher.

Keywords: study; work; skholé; teachers training.

«eis os meus, os meus mestres, a minha linhagem; eis, através deles, o que me une a todos»

(Camus, 2018, p. 23)

«Estudar é, realmente um trabalho difícil. Exige de quem o faz uma postura crítica sistemática. Exige disciplina intelectual que não se ganha a não ser praticando-a.»

(Freire, 1981, s/p) 
KAREN CHRISTINE RECHIA Y CAROLINE JAQUES CUBAS UMA SKHOLÉ PARA PROFESSORES: O ESTUDO COMO DIMENSÃO CONSTITUTIVA DO OFÍCIO DE PROFESSOR

\section{PARA INICIAR}

este texto é uma reivindicação. Reivindicação nascida de um diálogo que, atento ao que somos, exige que possamos continuar sendo. Ainda que não seja nosso propósito uma larga digressão sobre aspectos existenciais do ser, não é descabido afirmar que somos constituídos de história. O que somos, no presente, traz consigo referencias de passados, seja para segui-los e afirmá-los, seja para negá-los. Somos professores e, ainda que possamos atuar em distintos campos de conhecimento, existem saberes e fazeres que marcam, através dos tempos e dos espaços, nosso ofício. Não nos referimos aqui ao percurso histórico do professor como um sujeito, mas aos elementos que o conformam como figura pedagógica. Que pervivem, de forma acrônica, em seus gestos. Estas marcas, constitutivas do que somos, não devem ser renegadas. Conscientes, porém, de que são pouco enunciadas, pretendemos, nas páginas a seguir, trazer à tona alguns destes elementos pertinentes ao ofício considerando sua centralidade e, simultaneamente, certos obstáculos impostos a sua prática por lógicas utilitárias e mercadológicas do tempo presente.

Tornou-se corriqueiro, nos últimos tempos, a afirmação apressada de que professores precisam se adaptar aos tempos modernos. Em nome deste imperativo, vários dispositivos de controle e avaliação foram instituídos e novas tecnologias foram eleitas como possíveis salvaguardadoras de um futuro, impelindo professores e professoras ao domínio de ferramentas que tornassem suas aulas menos enfadonhas. Esta assertiva é facilmente observável quando trabalhamos com formação docente inicial e nos deparamos com alunos e alunas que, obstinadamente, buscam incorporar o uso de tecnologias na esperança de que estas garantam, de alguma forma, sucesso ou interesse pela aula planejada. Normalmente, as primeiras experiências são suficientes para demonstrar que as tecnologias, por si só, não fazem uma aula e que o ofício de professor é constituído por saberes e fazeres que antecedem e transcendem a escolha de métodos supostamente redentores (Masschelein e Simons, 2015; Biesta, 2017; Fernández Liria, García Fernández e Galindo Ferrández, 2017; Larrosa, 2018a; Larrosa e Rechia, 2018b).

Neste texto nos dedicaremos a alguns destes fazeres. Nossa intenção é, ao pensar o trabalho do professor como um ofício, ressaltar entre seus gestos característicos, o estudo. Para tanto, iniciaremos com notas introdutórias sobre a formação docente inicial e a condição do professor no tempo presente. Essas visam, em termos gerais, destacar características, limitações e apresentar as proposições que subsidiam nossa mirada ao ofício. Em um segundo momento, a partir da apresentação de relatos e ocorrências advindas de nossa atuação como professoras na formação docente inicial, ressaltamos a relevância do estudo como um gesto, um modo de vida e um elemento constitutivo do ofício que, por esta razão, precisa ter lugar nos anos iniciais da formação.

Deste modo, ao pensarmos a partir de nossas atividades na formação docente inicial, exigimos, assim como Albert Camus nas linhas que epigrafam este texto, 
KAREN CHRISTINE RECHIA Y CAROLINE JAQUES CUBAS UMA SKHOLÉ PARA PROFESSORES: O ESTUDO COMO DIMENSÃO CONSTITUTIVA DO OFÍCIO DE PROFESSOR

atentar àquilo que nos une, em uma linhagem, aos nossos mestres. Falemos, então, do diálogo, da linhagem, daquilo que somos e das interdições que, neste nosso presente, nos alijam daquilo que queremos ser.

\section{NOTAS SOBRE A FORMAÇÃo DOCENTE INICIAL E A CONDIÇÃo DE PROFESSOR NO TEMPO PRESENTE}

O diálogo ao qual nos refirimos acontece entre professoras. Teve seu início em 2016, por ocasião de um conjunto de atividades relacionadas ao projeto Elogio da Escola ${ }^{1}$ e pelo trabalho com a formação docente inicial, através de uma parceria firmada entre o Colégio de Aplicação da Universidade Federal de Santa Catarina e o Departamento de História da Universidade do Estado de Santa Catarina ${ }^{2}$. Tal parceria refere-se, entre outras atividades, ao acompanhamento dos Estágios Curriculares Supervisionados em História, etapa fundamental da formação docente inicial. Nestes estágios, estudantes da segunda metade do curso de licenciatura devem dedicar-se ao ofício de professor, em suas mais diferentes dimensões. Para tanto, cumprem uma extensiva carga horária em instituições escolares e dedicam tempo à observação dos espaços, dos alunos, das aulas e, finalmente, assumem a condição docente, sempre acompanhados pelas professoras da Unidade Escolar e da Universidade 3 . A atuação como professoras que acompanham e orientam este processo, na Escola e na Universidade, permite-nos não apenas a observação de inúmeros inícios -o início de cada um dos estudantes-, mas, especialmente, a abertura a uma experiência que tem algo de atípico e algo de ordinário, a saber, a experiência de se perceber como professoras que formam professores (Cubas e Rechia, 2017). Esta experiência nos instaura em uma curiosa condição, na medida em que nossa matéria de estudo é, também, nossa profissão. Antes, porém, de tratarmos das potencialidades do estágio e desta condição particular -que, de alguma maneira, possibilita e subsidia nossas reflexões-, falaremos brevemente da formação docente inicial, em termos de estrutura, intencionalidades e (im)possibilidades.

1. O projeto «Elogio da Escola» consiste em um conjunto de atividades voltadas a pensar a escola em sua dimensão pública, seus espaços, tempos, gestos e materialidades. Em 2016 o projeto organizou o "I Seminário Internacional Elogio da Escola», precedido por um seminário preparatório dedicado ao estudo do livro Em defesa da Escola: uma questão pública (2015), de Marteen Simons e Jan Masschelein. Este, ministrado pelo prof. Jorge Larrosa. Neste mesmo ano, promoveu igualmente um ciclo de cinema e um exercício teórico e prático, intitulado "Derivas» que, através de leituras, exercícios e caminhadas, propunha desenhar uma escola. Tais atividades resultaram na obra intitulada Elogio da Escola, publicada pela editora Autêntica em 2017 e pela editora Mino y Dávila em 2018.

2. Ambas instituições públicas, localizadas na cidade de Florianópolis, em Santa Catarina, estado da região sul do Brasil.

3. As Diretrizes Curriculares Nacionais para a formação docente inicial em nível superior preconizam 400 horas dedicadas ao estágio supervisionado. 

DO OFÍCIO DE PROFESSOR

A formação docente inicial é um tempo/espaço bastante particular. Ao assentar-se sobre a proposição de formar professores, pode, por vezes, engendrar a equivocada expectativa de abarcar aqueles que seriam os atributos incontornáveis para o desempenho do ofício. Mas, o que significa esta pretensão de formar professores? O que dá forma a um professor? E, ainda, quais os critérios adequados para a definição dos atributos acima citados? Em torno destas questões instauram-se amplos debates, dedicados, via de regra, a delimitar distinções entre saberes e o grau de relevância dos mesmos para o exercício da profissão. Um olhar panorâmico para o século XX nos possibilita perceber meandros destes debates, constituídos pelas mudanças sociais que afetam o ofício e, igualmente, pelas questões políticas que acompanham o desenvolvimento e a definição de fronteiras das distintas áreas de conhecimento. Tanto as questões sociais quanto os debates políticos acerca das áreas são relevantes à nossa discussão no sentido em que delimitam -e limitam-, em certa medida, algumas das possibilidades de exercício do ofício docente. (Julia, 2001; Rüsen, 2006; Bittencourt, 2011; Koselleck, Meier, Günther e Engels, 2013).

No que tange às questões políticas referentes às fronteiras, distâncias e aproximações que caracterizam as áreas de conhecimento, é suficiente ressaltar a existência de uma persistente tensão entre aqueles que seriam os conhecimentos específicos de uma área determinada -e que deveriam ser ensinados- e aqueles considerados pedagógicos que, percebidos de forma bastante reducionista, diriam respeito às ferramentas metodológicas que garantiriam alguma sorte de adequação dos conhecimentos científicos aos espaços escolarizados. O debate se coloca então entre aqueles que ressaltam a centralidade dos conhecimentos específicos de uma área e aqueles que defendem os conhecimentos didáticos como primordiais para o exercício do ofício docente (Rüsen, 2006). Ainda que tal tensão seja recorrente, torna-se cada vez mais consensual -ao menos enquanto discurso formativo- a necessidade de se equalizar aqueles que passaram a ser chamados comumente de saberes docentes e que, uma vez apropriados, garantiriam o exercício profissional do ofício (Tardif, 2018). Tais saberes, cotidianamente mobilizados, seriam assim, elementares. Envolveriam o conhecimento específico de uma área ou disciplina, os conhecimentos didático-pedagógicos para o ensino desta disciplina e, finalmente, os conhecimentos psicossociais, que garantiriam uma aproximação à realidade dos alunos, compreendendo esta realidade como um conjunto de condições sociais e psicológicas que influenciariam fortemente o percurso formativo dos estudantes. Estes saberes estão presentes -com mais ou menos veemência- nos cursos de formação inicial de professores (as licenciaturas) ${ }^{4}$. Ao abordá-los aqui, empregamos propositalmente o condicional não para negar sua importância. Acreditamos,

4. Conforme o texto das Diretrizes Nacionais Curriculares para a formação docente inicial, no inciso $6^{\circ}$. do artigo $3^{\circ}$. 
KAREN CHRISTINE RECHIA Y CAROLINE JAQUES CUBAS UMA SKHOLÉ PARA PROFESSORES: O ESTUDO COMO DIMENSÃO CONSTITUTIVA DO OFÍCIO DE PROFESSOR

contudo, que estes saberes, relevantes por certo, não encerram todas as facetas do ofício de professor.

\subsection{Saberes de ofício}

Certos elementos fundamentais parecem não se enquadrar nos saberes acima elencados e, por mais que pareçam óbvios, precisam ser anunciados. Falamos aqui de hábitos, maneiras, atitudes que constituem o ofício, mas que não estão categorizados ou enquadrados como conhecimento e que, portanto, não costumam ser matéria de estudo ao longo da formação de professores. Tratam-se, porém, de elementos incontornáveis, ao mesmo tempo abstratos e absolutamente materiais e ordinários. Nos referimos aqui àqueles elementos que dão materialidade ao ofício. Que permitem perceber-nos como partícipes de uma comunidade, alinhados a uma sorte de tradição (Larrosa, 2018a, p. 131). Em Nous autres professeurs, texto escrito em 1969 pela helenista Jacqueline de Romilly e apresentado pela mesma como uma profissão de fé sobre o métier de professeur diante das crises que emergiam no sistema educacional francês de então, Romilly nos deixa ver alguns destes elementos. Ao falar dos desafios impostos pela corriqueira prática de avaliar e atribuir nota, tece considerações sobre as colossais proporções das pequenas decisões, nas quais demoramo-nos, por vezes, em detalhes, argumentos e indefinições. Tais minúcias são apresentadas como o reverso da probidade e consciência que, segundo a autora, caracterizam o ofício. Em suas palavras: «Estas são as marcas do ofício, como os calos nas mãos dos trabalhadores. Nós não temos que negá-las» (Romilly, 1991, p. 40).

São vários, podemos afirmar, os gestos do ofício que marcam o corpo e constituem o que é ser professor. Tais gestos e modos de fazer são comumente formados no percurso, através da prática, das lembranças, das inspirações, dos saberes advindos da leitura e da experiência. Não podem ser reivindicados, portanto, como conhecimentos específicos de uma área ou outra e não podem, igualmente, ser transpostos. São, porém, característicos de um ofício. Indispensáveis, ordinários e, muitas vezes, imperceptíveis. Figuram, talvez, nas zonas de não conhecimento, das quais nos fala Agamben. Ao ensaiá-las, afirma que articular uma zona de não conhecimento «não significa, de fato, simplesmente não saber, não se trata somente de uma falta ou de um defeito. Significa, pelo contrário, mantermo-nos na exata relação com uma ignorância, deixar que um desconhecimento guie e acompanhe nossos gestos» (Agamben, 2014, p. 166). Acreditamos, por isso, que é imprescindível assomá-los durante o período de formação docente inicial. Não para domá-los, mas para dar a eles a devida atenção. Nos referimos àqueles gestos e maneiras que passam desapercebidos, que não recebem alarde e que, ainda que invisíveis, fazem-se invariavelmente presentes no espaço-tempo de uma aula. Dentre eles, salientamos aqui o estudo. Não o estudo voltado ao desenvolvimento de uma aprendizagem pontual, mas antes, o estudo como gesto, na medida em que instaura um ethos, e 

DO OFÍCIO DE PROFESSOR

como forma de vida (Agamben, 2015). Como dimensão constitutiva do ofício de professor.

Por mais que pareça evidente afirmar o estudo como intrínseco ao ofício, amparamo-nos em Gerard Genette para inferir que definições por demais simples e aparentemente evidentes incorrem no inconveniente de se limitar e, de maneira similar, limitar-nos à simplicidade e evidência. Tais definições arriscam anuviar nosso olhar, encobrindo as dificuldades, tensões, sutilezas e fronteiras que nos auxiliam a delinear qual é, afinal, o lugar de estudo em nosso ofício (Genette, 1966). Quando falamos em lugar ocupado, não nos referimos a uma função. Não se trata aqui de pensar para que serve o estudo. A atribuição de uma justificativa utilitária seria, a nosso ver, a própria negação do que o estudo preconiza. Ao tratarmos o estudo como uma forma de vida, gostaríamos de ressaltar a ideia de forma e considerar, assim, que esta vida não pode ser separada de sua forma. Tratamos de um professor que estuda. Que estuda não para aprender algo, mas porque é o gesto de estudar, entre outros, que o permite habitar o ofício ${ }^{5}$. Cremos, portanto, muito mais relevante que buscar uma função, pensar em termos de presença (Gumbrecht, 2010). Pensar como somos afetados pelo hábito estudioso e como isso dá forma a maneiras particulares de ser professor. Maneiras particulares, mas, conforme dito anteriormente, identificáveis como características deste ofício. Eis porque nos propomos aqui a pensar que o estudo nos forma e nos dá forma. E, simultaneamente, somos incitados a questionar quais as formas de estudo que (não) se fazem possíveis no tempo presente, no processo de formação e exercício do ofício docente. Tal questão, direta e aparentemente ingênua, visa desordenar certezas. Visa impor a necessidade de uma resposta. Uma resposta que requer busca, atenção e disciplina afinal «a verdade nunca é produto de uma boa vontade prévia, mas resultado de uma violência sobre o pensamento" (Deleuze, 2006, p. 15). É preciso desnaturalizar a presumida presença do estudo no ofício como elemento óbvio para perceber que, no tempo presente, ele nos parece cada vez mais impróprio, cada vez mais ausente.

\section{2. "Como um oásis na trama dos dias"}

A percepção desta ausência e desta impropriedade não é apenas uma impressão. Ela se manifesta em diferentes instâncias: desde a formação inicial até as exigências e demandas impostas aos professores dos distintos níveis de ensino. Ao observarmos os documentos que regem a formação inicial e as exigências profissionais feitas aos professores, percebemos que estas acabam por moldar formas de ser professor que não dão espaço e, particularmente, tempo para determinadas práticas -por mais

5. Com Agamben: "Habito es um frecuentativo de habeo (tener): habitar es um modo especial del tener, um tener tan intenso como para no poseer nada más. A fuerza de tener algo, lo habitamos, nos volvemos suyos» (2018, p. 13) 
fundamentais que sejam consideradas- como o estudo. Isso porque o estudo, da maneira como o compreendemos aqui, não traz consigo uma finalidade prática. Não atende aos apelos de um mercado. Não pode ser quantificável ou capitalizável. A formação docente inicial, por outro lado, tem cada vez mais fundamentando-se em uma lógica de aprendizagem, de desenvolvimento de competências e habilidades voltadas, na maioria das vezes, à garantia de inserção no mercado de trabalho e atuação profissional adaptada a lógicas produtivistas. Ao tratar da educação como possibilidade de intervenção -e não adaptação- no mundo, Paulo Freire parece corroborar tais impressões ao afirmar que «é uma imoralidade que se sobreponha, como se vem fazendo, aos interesses radicalmente humanos, os do mercado» (Freire, 2015, p. 98). Tal lógica, colonizada por uma linguagem/racionalidade de mercado não é recente e, tampouco, uma particularidade do caso brasileiro (Biesta, 2017).

Pensando as condições de exercício deste ofício no presente, Masschelein e Simons identificam imperativos que, nas palavras dos autores, terminam por «domar (os professores) em nome das exigências atuais do mercado, do consumo ideal e da empregabilidade» (Masschelein e Simons, 2015, p. 140). É importante ressaltar que, quando se referem ao professor, tratam de uma "figura pedagógica que habita escola» (p. 113). Ele é pensado, desta maneira, apenas através das relações que estabelece -com seus alunos e com sua matéria- no exercício de seu ofício e no espaço no qual este ofício se realiza, a saber, a escola ${ }^{6}$. São justamente estas relações particulares estabelecidas com os estudantes e com a matéria que vem sendo fragilizadas pela primazia de uma lógica da aprendizagem colonizada, reafirmamos, por uma racionalidade mercadológica. Tal racionalidade atua, entre outros aspectos, no sentido de neutralizar a relação de amorosidade que, para os autores, é igualmente constitutiva daquilo que implica ser professor. ${ }^{7}$ À amorosidade como conformadora do ofício é atribuída importância similar que ao conhecimento e a metodologia. Ela materializa-se através de pequenos gestos, falas e escutas que manifestam amor pelo assunto e pelos alunos (Masschelein e Simons, 2015, p.76). Este amor pelo assunto diz respeito à atenção e dedicação apaixonada que um professor entrega à sua matéria de estudo e que é perceptível na maneira como ele, por vezes, personifica esta matéria no curso de uma aula. Este movimento é expresso de forma bastante pessoal por Romilly, nas palavras que transcrevemos a seguir:

6. Escola compreendida aqui como um espaço pedagógico. Para os autores «o espaço pedagógico não é, pois, uma infraestrutura ou uma instituição preexistente, em que mestre e criança se introduzem para produzir o aprendizado. O espaço pedagógico abre-se com a interrupção da pedagogia e da instituição, com a separação do aluno em relação a si mesmo.» (Masschelein e Simons, 2014, p. 39)

7. A noção de amorosidade baseia-se, entre outras, na concepção arendtiana de amor mundi. No que concerne ao professor ou professora, este amor se expressa na abertura e compartilhamento de um mundo comum. 

DO OFÍCIO DE PROFESSOR

A hora da aula é como um oásis na trama dos dias: é uma hora reservada ao conhecimento, à verdade, à inteligência. É uma hora em que nada mais importa que a demonstração de um teorema, a exatitude de uma tradução, a beleza literária de uma obra. E eu diria que esta hora representa, em certo sentido, um privilégio raro: pois há alegria maior que a de fazer com que os outros compreendam aquilo que sabemos e amamos? $(1991, \text { p. } 33)^{8}$

Através desta relação amorosa com a matéria, o professor, ao falar dela, instaura-se em um presente a ser compartilhado com alunos e alunas. Neste "oásis na trama dos dias", do qual fala Romilly. Num presente a parte do tempo cotidiano e que exige atenção ao assunto. Esta relação com a matéria, que certamente não pode ser ensinada, apenas experienciada (por alunos e professores), traz consigo exigências como a prática, a perseverança, a dedicação, a atenção e, fundamentalmente, o estudo.

\subsection{Profissionalizaçao, flexibilização e as fendas do presente}

Por mais que sejam imprescindíveis ao ofício docente, certas práticas vão de encontro às demandas de produtividade, velocidade e atualização que caracterizam nosso tempo presente, sendo consideradas por vezes enfadonhas ou inoportunas Para abordar as maneiras através das quais professores e professoras tem sido alijados daquilo que, em princípio, seria constitutivo de seu ofício, Masschelein e Simons (2015) dedicam-se à análise das categorias de profissionalização e flexibilização.

A primeira delas, a profissionalização, apresenta nuances delicadas. Não se trata de desconsiderar a relevância das lutas em torno da valorização, legitimidade, direitos e dignidade reivindicados historicamente ao exercício do ofício docente. Por outro lado, a profissionalização torna-se um problema quando implica na submissão do professor aos imperativos da sociedade que o profissionaliza. Neste sentido, é importante atentar ao fato de que a ideia de profissionalização vem sendo atrelada a obrigatoriedade de produzir resultados quantificáveis em um tempo cada vez mais estreito. A profissionalização, assim, acarreta o risco de formar um professor alheio ao que seria, de fato, sua responsabilidade pedagógica na medida em que impõe a ele a necessidade de cumprimento de demandas técnicas ou burocráticas. Exige-se do professor que atue positivamente no desenvolvimento de competências e habilidades que possam ser empregados em tarefas concretas, úteis às necessidades do mundo profissional. O professor torna-se, segundo este imperativo, um mero prestador de serviço.

De maneira similar, a valorização de um certo profissionalismo neoliberal exige do professor ou professora flexibilidade, no sentido de se adaptar e se tornar disponível a exigências exteriores ao seu ofício. Diante disso, a relação com a

8. Tradução nossa. 
matéria de estudo torna-se secundária em prol da necessidade de desempenhar performances que atendam à determinados padrões de empregabilidade e de algo que se convencionou chamar «qualidade» - sempre quantificável e capitalizável.

Muito mais relevante que o desenvolvimento de talentos ou o cumprimento de metas inflexíveis e previamente estabelecidas, a responsabilidade pedagógica diz respeito à formação do interesse e atribuição de autoridade às coisas do mundo. Os conhecimentos e os modos de fazer de um professor não podem ser reduzidos a competências obtidas por meio de técnicas ou treino. Recorremos novamente a Paulo Freire, quando afirma que "formar é muito mais do que puramente treinar o educando no desempenho de destrezas» (Freire, 2015, p. 16).

Esta colonização dos modos de ser professor em prol de uma lógica produtivista, quantitativa, de aceleração, que privilegia resultados rápidos, afeta as possibilidades de relação com o tempo exigidas pelo estudo, o qual requer atenção, disciplina e recolhimento. Em um texto de data imprecisa, o filosofo tcheco-brasileiro Vilém Flusser nos diz que "a posse de tempo é liberdade» e complementa: «ou eu o faço parar, afim (sic) de manipulá-lo e submetê-lo às minhas ordens. Ou sou objeto do tempo" (Flusser, s/d, p.1). Essa relação estabelecida com um tempo acelerado, que convulsiona aqueles que dele não se apossam, marca nosso presente. Levada aos extremos, resulta naquilo que Jonathan Crary caracteriza como $24 / 7$, a saber, um esquema arbitrário regido pela plena colonização do tempo pela lógica do mercado. Segundo o autor, «hoje são raros os momentos significativos na existência humana (com a exceção do sono) que não tenham sido permeados ou apropriados pelo tempo de trabalho, pelo consumo ou pelo marketing» (Crary, 2016, p. 24). Vivemos, atualmente, em um presente iminente, reagindo àquilo que se coloca imediatamente à nossa frente. Esta forma de estar no presente afeta, indubitavelmente, nossas relações com o tempo e, consequentemente, nossa maneira de habitar o ofício.

Ao tecer considerações sobre a palavra ofício, Jorge Larrosa ressalta a inseparabilidade entre aquilo que se é e aquilo que se faz. Assim, "O ofício é o que faz com que alguém se comporte de um modo consequente com aquilo que é» (Larrosa, 2018a, p. 315). Ao pensarmos o estudo como constitutivo do ofício de professor, estamos destacando seu caráter habitual, como um modo de fazer encarnado, que não vislumbra um fim. Este estudo não persegue a incorporação de um saber ou a aquisição de uma habilidade, uma vez que ele é, em si, um gesto, um puro meio (Agamben, 2015). O estudo, neste sentido, emerge como contraposição imediata às obrigações impostas por este presente estendido na medida em que exige desprendimento de si e de expectativas imediatistas em nome da possibilidade de experiência. Este tempo presente acelerado, no qual somos -e formamosprofessores, não parece ser, assim, o tempo do professor. Ser professor emerge como condição anacrônica, na medida em que, alocado neste presente, não pode se submeter a ele. Do contrário, é buscar, incessantemente, através do estudo, as fendas deste presente. A instauração de um tempo outro. Um tempo lentificado, 

DO OFÍCIO DE PROFESSOR

possibilitador da atenção, do exercício, do cultivo, da formação. Ainda que o ato de pensar o trabalho de um professor ou professora em termos de ofício possa trazer consigo certa inadequação, é esta mesma inadequação, acreditamos, o que garante a contemporaneidade da proposição.

Como professoras que atuam diretamente na formação docente inicial, acompanhando e orientando estágios, nosso ofício torna-se nossa matéria de estudo. Buscamos, neste sentido, atentar às facetas acrônicas da profissão. Acreditamos que o estudo é uma delas. Deste modo, nos dedicamos a pensar as possibilidades de estudo do/no ofício e a escola como o espaço privilegiado para o desenvolvimento deste exercício. A escola torna-se, assim, escola para os alunos da educação básica, regularmente matriculados, para os alunos em estágios, que devem observar e exercitar o ofício (muitos, pela primeira vez) e para nós mesmas, quando perseguimos uma sorte de skholé e nos dedicamos ao estudo meticuloso dos nossos modos e maneiras de ser/fazer.

\section{NOTAS SOBRE O ESTUdO COMO GESTO PEDAGÓgICO: O QUE FAZ COM QUE UM PROFESSOR (TAMBÉM) SEJA PROFESSOR}

Ao entendermos o trabalho do professor como um ofício, ao identificarmos certos modos de fazer, passamos também a compreender que ele, desta forma, só é possível, ou só é capaz de habitar um espaço escolarizado. Na obra Em defesa da escola: uma questão pública, Masschelein e Simons (2015) apontam vários elementos que compõem uma concepção do que é o escolar, que nos inspira e conduz. Escolhemos seguir este itinerário no sentido de considerarmos as materialidades envolvidas em ações e práticas docentes no âmbito escolar.

Os autores reivindicam a escola como um lugar do tempo livre ou, melhor dizendo, a escola como instituição que, através da combinação peculiar entre tempo, espaço e matéria cria uma forma que comporta um tempo livre e suspenso da sociedade, a democratização de um tempo livre. Temos aqui a noção de skbolé, apropriada e referenciada neste texto.

Ao tornar o conhecimento como matéria de estudo, suspende-se uma certa utilidade, separa-se este conhecimento de seu uso convencional e da apropriação pelos grupos sociais. A suspensão evidencia a separação de tempos e espaços que a escola promove -ao menos em sua acepção grega- e faz com que «as crianças podem parecer como alunos, os adultos como professores, e os conhecimentos e habilidades socialmente importantes como matéria da escola». (2015, p. 36). Contiguamente, quando algo é afastado de seu uso habitual e disponibilizado para estudo, o elemento que surge seria o da profanação. Profanar, do mesmo modo, é tornar público, disponibilizar as coisas "para uso livre e novo", colocar algo sobre a mesa (2015, pp. 40-41). A suspensão e a profanação permitem um terceiro elemento que é o de promover a atenção, de criar o interesse pelo mundo. Porém o interesse aqui não é compreendido como uma escolha, uma motivação pessoal, e sim algo 
KAREN CHRISTINE RECHIA Y CAROLINE JAQUES CUBAS UMA SKHOLÉ PARA PROFESSORES: O ESTUDO COMO DIMENSÃO CONSTITUTIVA DO OFÍCIO DE PROFESSOR

que está fora de nós, que nos leva a estudar, para o qual a nossa atenção deve ser canalizada, neste caso, o próprio mundo.

Um quarto componente diz respeito à tecnologia, considerada tanto em seus artefatos, como a cadeira e a carteira, o quadro-negro, o livro e ambientes como a sala de aula, a própria escola, quanto nos métodos de ensino, como os ditados, as apresentações orais, os exercícios variados, os exames, entre outros. A proposição fundamental aqui não é considerar as tecnologias como instrumentos formadores em série, tampouco como técnicas manipulatórias ao à serviço de uma geração e de suas ideias políticas. Nas palavras dos autores, «as tecnologias da educação escolar são técnicas que, por um lado, engajam os jovens e, por outro, apresentam o mundo; isto é, focam a atenção em alguma coisa.» (2015, p. 65). E, de certa, forma é o que torna possível o tempo livre.

Uma outra noção inerente ao espaço escolar é de igualdade, e esta diz respeito a uma igualdade como princípio, no sentido que a coloca Rancière em $O$ mestre ignorante (2002), de um ser capaz de. Não se trata de negar as questões individuais, o contexto do aluno, as diferenças intrínsecas ao processo de ensino, mas sim de tomar a igualdade como algo prático, inerente ao trabalho do professor e da escola, que "coloca a todos numa posição inicial igual e fornece a todos a oportunidade de começar.» (Masschelein e Simons, 2015, p. 71). Neste sentido é o professor quem verifica cotidianamente esta igualdade, quem separa as coisas de seu uso normal e apresenta aos estudantes, e os desafia a uma "capacidade e a possibilidade de falar (de uma maneira nova, original, que cria novas ligações entre palavras e coisas), de agir, de ver, etc.» (2015, p. 70). É o professor que crê, antes mesmo da escola, que todo aluno pode se interessar por algo, e que as formas de diferenciação se dão a partir dessa premissa, e não o contrário.

E é a partir da figura do professor que, como sexto destaque, Masschelein e Simons falam do professor amateur. O ponto aqui não é descaracterizar o professor como profissional mas, como já inferimos na primeira parte, agregar ao seu papel um intrínseco amor pelo assunto, pela matéria de estudo e que, consequentemente, envolve seus alunos. Ao mesmo tempo é um amor que não pode ser ensinado: nem aos seus alunos, nem aos professores que ele forma. Quem sabe o que ele possa, num gesto igualmente potente, seja "fechar a porta da sala de aula» e tentar produzir ali uma presença no presente, este lugar temporal no qual queremos que nosso aluno se situe, que pode ser atingido, em parte, pelos exercícios e materiais, por uma certa disciplina, mas cuja proposição depende, em muito, do professor e de sua própria presença.

Mas certamente Pennac nos dá alguns indicativos do que pode compor esta presença:

É imediatamente perceptível a presença do professor que habita a sala de aula. Os alunos a percebem desde o primeiro minuto do ano, nós todos temos essa experiência: o professor acaba de entrar, ele está totalmente lá, e isso se vê pela sua maneira de olhar, 

DO OFÍCIO DE PROFESSOR

de cumprimentar os alunos, de sentar, de tomar posse da mesa. Ele não se dispersou por medo das reações deles, ele não está fechado em si mesmo, não, ele está dentro do que faz, logo no começo ele está presente, distingue cada rosto, a turma existe sob o seu olhar (2008, p. 105).

A presença do professor certamente está relacionada a sua experiência e ao seu conhecimento, mas nos chama a atenção, na formação inicial, que esta também pode ser exercitada nesse estar na sala de aula, nesta preparação da aula e de si para este momento. Neste empenho de estar em sala, outros saberes e recursos são mobilizados; um certo tipo de disciplina e de técnicas - não as que se separam do próprio fazer e por isto são formas esvaziadas - mas as que afluem para o estudo, o interesse e a atenção.

Na sequência, os autores abordam uma questão de preparação, para inferir que a escola é um lugar de preparação. Porém não uma preparação que visa o mercado de trabalho ou a entrada na universidade -no entanto estas perspectivas também perpassam o ambiente escolar e as várias ideias de escola que os diferentes grupos que atuam na escola possuem- mas uma preparação em si. E esse estar bem preparado, estar em forma gira em torno da matéria, que envolve, como defendemos neste texto, o estudo e a prática. Pode-se dizer, inclusive, que é um tipo de «aprendizagem sem uma finalidade imediata» (Masschelein e Simons, 2015, p. 91).

Por fim, a questão que encerra, ou ao menos delimita, certa forma do que é o escolar diz respeito a responsabilidade pedagógica. Imbricada nesta questão está uma ideia de formação e educação, que para os autores difere da socialização ou do desenvolvimento de talentos, posto que «trata-se de abrir o mundo e trazer o mundo (palavras, coisas e práticas que o compõem) para a vida» (2015, p. 98). E o espaço escolar seria este tempo e espaço liberados para o próprio encontro com o mundo que, por outro lado, não é um encontro individual, pois não principia de um interesse ou do mundo imediato de cada um, outrossim de uma dimensão democrática e política que apresenta este mundo compartilhado.

A responsabilidade pedagógica se evidencia, por um lado, em suspender a função imediata das coisas na formação do aluno e por outro, em despertar um interesse às palavras, às coisas e às maneiras de fazer que impulsionam um mundo comum. Reiteramos que nossa intenção, ao evidenciar estes destaques, é a de trazer à luz elementos que nos auxiliem a olhar para a escola e para a sala de aula como espaços formadores das alunas e dos alunos na experiência da docência. Outrossim, não é o de enunciar - como dizem os próprios autores - uma escola ideal, mas de explicitar "O que faz com que uma escola seja uma escola, e, consequentemente, diferente de outros ambientes de aprendizagem (ou de socialização, ou de iniciações).» (2015, p. 29). 
KAREN CHRISTINE RECHIA Y CAROLINE JAQUES CUBAS UMA SKHOLÉ PARA PROFESSORES: O ESTUDO COMO DIMENSÃO CONSTITUTIVA DO OFÍCIO DE PROFESSOR

\subsection{A aula como um lugar público}

Ao atribuirmos importância a esta concepção, algumas observações emergem dos cadernos de anotações dos estagiários:

... Assim, por ter aula com uma professora e observar a aula da outra, existem momentos onde o que discutimos na disciplina com a professora Carol acaba por transparecer na metodologia e execução da professora Karen, nos ajudando a compreender conceitos e discussões que, por vezes, tendem a abstração. Podemos notar então como a pesquisa também interfere no seu fazer aula, pois os dois campos (a pesquisa e o fazer aula) se retroalimentam, possibilitando uma pesquisa baseada na experiência e uma experiência baseada na pesquisa. (Caderno de anotações das observações, julho/2018).

O que eles chamam de pesquisa constitui-se mais como campo de observações, leituras e conversações estabelecidas entre nós duas. De tal forma que não há prazos estabelecidos ou relatórios a fazer, como numa pesquisa institucional, mas que por força desta configuração intensiva de um tempo e espaço de estudo ao qual nos temos debruçado, tende a tornar-se institucionalizada, como decorrência deste processo. Ou seja, não nomeamos ou criamos hipóteses configurando um campo de investigação e depois procuramos torná-lo preenchível, palpável, «medível». Ao contrário, ao perceber que nossa insistência em buscar outros elementos para compreender este espaço fluido na formação de professores e seus desdobramentos - notadamente na filosofia da educação - constituiu um lócus estudioso entre nós, identificamos que este era um movimento não só possível, mas importante na atuação destes professores em formação. Desta forma, nosso empenho passa ser o de observar e, ao mesmo tempo, de incentivar, criar, dar a ver este "modo estudioso" entre os estagiários.

De certo modo, fomos nos afastando de uma ideia de um "aprender» a ser professor - não que uma certa dimensão do aprender não esteja ali presente - mas nos aproximando de fundamentos que estão na composição de uma aula e que, por sua vez, podem «iluminar» tudo que está a sua volta. Dizendo de outra maneira: a aula não seria o produto final deste processo, mas o primeiro plano a ser observado e decomposto. Numa analogia ao cinema, o plano fílmico sobre o qual o estudante se debruça, para compreender com quais movimentos de câmera, com quais luzes, com que personagens, com que sons e narrativas ele pode compor a mesma cena ou criar outras. ${ }^{9}$ Como o cineasta, ele adquire a capacidade de imaginar, mas somente

9. Um diálogo interessante sobre as semelhanças e diferenças entre um plano de filme e um plano de aula teve lugar no II Seminário Internacional «Elogio da Escola»: sobre o ofício de professor, em Florianópolis, no ano de 2018. O diálogo entre o professor e filósofo da educação Jorge Larrosa e o cineasta brasileiro Cristiano Burlan, se transformou em texto e está no livro Elogio ao ofício de professor, ainda no prelo. 
porque ele já assistiu a inúmeros filmes e talvez tenha repetido vários deles, com um olhar atento, paciente - ou insistente - e, muitas vezes, solitário.

No processo de acompanhamento das observações e elaboração dos planos de aula, há um empenho de nossa parte para que os estagiários atentem mais à forma que ao conteúdo. Isso acaba por se revelar nos relatos de observação, incluindo a dificuldade em relação a esta inversão, como registra esta estagiária:

eu pessoalmente aprendi muito mais sobre a Revolução Francesa com a aula da professora XXX para o ensino médio do que na minha graduação - em meu diário de anotações eu constantemente precisei me lembrar de observar a turma de fato e não fazer anotações sobre a aula (Caderno de anotações das observações, julho/2018).

A aula, do ponto de vista da estudante, caracterizar-se-ia pelo conteúdo histórico e por uma certa maneira particular de ensiná-lo. O viés que propomos considera outros marcos neste processo. A aula é justamente o lugar onde grande parte do estudo sobre o ofício do professor intercorre e não pode ser definida apenas pela transmissão de um conteúdo e pela singularidade com que esta transmissão acontece.

Ao situarmos a aula no centro da diferenciação entre aprender e estudar um ofício, estamos afirmando o papel público do ensino e do professor, que «não está conectado com seu conhecimento ou maestria, mas com sua atenção em direção a algo em comum e com seu convite (e inclusive suas ordens) aos estudantes para que façam o mesmo» (Cornelissen, 2011, p. 68). Portanto é público «não no sentido de que o professor esclarece algo que antes estava oculto, mas no sentido de que o professor ilumina perguntando/pedindo atenção sobre algo.» (ídem).

A discussão que Cornelissen desenvolve a partir da figura de Jacotot, personagem de "O mestre ignorante», conhecida obra de Jacques Rancière, nos afeta em nossas práticas como formadoras de professores, justamente por que se atém -e como assim também o compreendemos- ao papel público do ensino e do ensinar. Ao mesmo tempo, como nos diz o autor,

é importante enfatizar, porém, que esta maneira de repensar e reaproveitar o papel público de ensinar não pode ser entendida como método, no sentido de que algo que pode ser aprendido o adquirido em termos de conhecimento, competências ou de habilidades. No entanto, o exemplo de Jacotot sugere que qualquer um pode preparar-se para prestar atenção (Cornelissen, 2011, p. 69).

\subsection{Maneiras de ser professor}

Não há, portanto, um método para ensinar a ser professor, nem no sentido de uma vocação orientada a competências e aprendizagens individuais. Aliás, a noção de aprendizagem, ou de um ambiente de aprendizagem para esta formação docente, vai de encontro ao que estamos propondo na formação inicial. Por isso consideramos esta formação mais próxima de um ofício do que de uma profissão. 
KAREN CHRISTINE RECHIA Y CAROLINE JAQUES CUBAS UMA SKHOLÉ PARA PROFESSORES: O ESTUDO COMO DIMENSÃO CONSTITUTIVA DO OFÍCIO DE PROFESSOR

Elegemos a ideia de ofício e não de profissão, não só pela "contaminação" desta pela ideologia do profissionalismo e de sua associação com competências e resultados, mas porque nós reconhecemos, ao falar de ofício, naquilo que, conforme Larrosa e Rechia,

incorpora uma série de hábitos que constroem um ethos, um costume, um modo de ser e de atuar, um modo de viver; nisso de que o ofício deve ser exercido com devoção, entregando-se a ele, respeitando-o, e sem qualquer sentimento de opressão sobre nossa natureza em função do nosso dever; isso que implica compromissos e, às vezes, lutas; nisso de que o ofício de professor implica questionar tudo; e, sobretudo, fugindo de toda solenidade e de toda grandiloquência; reconheço-me também no que o ofício tem de ínfimo e de cotidiano, de algo que se faz a cada dia (e não em momentos especiais) e de um modo sempre menor, com gestos mínimos, modestos, quase desapercebidos, sem espetáculos nem artifícios (2018b, pp. 319-320).

O que consideramos portanto, neste processo, são práticas de estudar a escola e a aula, não para aprender suas lógicas supostamente em constante transformação no âmbito da sociedade, ou para formar especialistas na aprendizagem, mas talvez, como observa Cornelissen, "oferecer aos (futuros) professores um tempo e um espaço (separados) para o exercício e a experimentação (experiência)» (2011, p. 70).

Por isso o foco não está num método docente, mas na ativação de uma experimentação que poderia ser caracterizada a partir de uma máxima ranceriana: e tu o que vês? E tu o que pensas? E tu o que fazes? Uma experimentação desenvolvida através de observações, pensamentos e práticas que coloquem a escola -e por conseguinte a sala de aula- como matéria de estudo, como o desenvolvido por Masschelein e Simons (2015) ao demarcarem o que é o escolar. Voltamos à citação de Cornelissen para sublinhar, além da experimentação, a ideia de oferecer aos professores em formação, um tempo e um espaço separados. Essa é a lógica mesma da skholé.

Ao optar por afirmar o estudo como constitutivo da formação inicial na trajetória que produz, de certa forma o professor, compreende-se nesta trajetória um saber fazer, que por sua vez tentamos descolar tão somente do aprendizado e aplicação de metodologias. Como também estamos seguindo uma concepção de ofício para o trabalho do professor, talvez pudéssemos denominar este saber fazer como «maneiras».

O estudante de estágio certamente partilha de um conjunto de regras comuns e legadas, de um conjunto de fazeres que o fazem identificar e diferenciar o trabalho do professor de outros trabalhos - ou pelo menos deveriam - ao mesmo tempo que desenvolve um jeito próprio, singular de colocar-se no exercício da docência. Em realidade, é o desenvolvimento desse jeito singular somado aos saberes docentes em questão (Tardif, 2018; Freire, 2015) que fazem com que ele perceba que não há como "aprender» este ofício, mas tão somente, observá-lo, prepará-lo, repeti-lo, enfim, estudá-lo. 

DO OFÍCIO DE PROFESSOR

Ainda em relação à metodologia Larrosa e Rechia coloca em xeque a palavra ao identificar uma certa "tirania metodológica" nas instituições educativas atuais, no sentido de uma padronização dos métodos, de um cerceamento e, no limite, desqualificando o trabalho intrínseco do professor. Afirma, dessa forma, suas próprias maneiras de fazer:

...creio que o que procuro fazer é colocar em marcha uma série de procedimentos orientados ao pensamento (seja o que for). Não à assimilação de conteúdos, à obtenção de resultados de aprendizagem ou à aquisição de competências, mas a colocar em jogo o melhor da sensibilidade e da inteligência de cada um dos participantes em um jogo de leitura, escrita e conversação que não pode (nem quer) antecipar seus resultados (2018b, p. 302).

Sua crítica fundamenta-se, entre outras coisas, na contramão da produção de resultados e eficácias educativas.

Pois bem, no interior dessa noção de «maneiras» de fazer, o que os estagiários devem observar? Uma infinidade de gestos pedagógicos. E por "gestos» compreende-se "como um movimento do corpo ou de um instrumento unido ao mesmo, para o qual não se dá nenhuma explicação causal satisfatória. A fim de poder entender os gestos assim definidos, é necessário descobrir seus significados» (Flusser, 1994, p. 10). Dessa forma, para Flusser, estamos limitados a uma leitura intuitiva deste mundo dos gestos, que por sua vez é decodificado pela própria cultura, porque articula em si um símbolo e um significado. No entanto as explicações causais, científicas, por mais que sejam substanciais a sua compreensão, não a atingem plenamente. A verdade é que um gesto «o é porque representa algo, porque com o mesmo só se trata de dar um sentido a alguma coisa» (Flusser, 1994, p. 11).

Portanto, ao mesmo tempo em que prescrevemos aos estudantes a percepção de uma gestualidade simbólica e comum, realçamos, à maneira de uma «leitura intuitiva", aquilo que nos escapa, que complexifica o papel do professor, revelando certa singularidade. Esta combinação entre singular e comum no tocante ao ofício é ponto crucial no tempo das observações; é onde acreditamos que os estudantes possam perceber este sentido maior do gesto: o de, mais do que representar, apresentar algo, dar sentido à alguma coisa.

O papel exercido pela a professora coorientadora ${ }^{10}$, a professora da instituição escolar, talvez seja o que mais promova consciência do ofício. Ao preparar suas aulas

10. No documento elaborado pela disciplina de História da referida instituição escolar, que rege o estágio curricular, o professor da escola é denominado de coorientador, cuja «função é zelar para que as intervenções propostas no estágio estejam em consonância com o processo de ensino-aprendizagem em que se encontra a turma. Para tanto, acompanha e orienta, em parceria com o professor de Prática de Ensino, as atividades propostas pelos estagiários. O professor coorientador é, portanto, a principal referência do estudante de Estágio Curricular Obrigatório na escola». (Orientações para a realização do Estágio Curricular em História, 2016). 
KAREN CHRISTINE RECHIA Y CAROLINE JAQUES CUBAS UMA SKHOLÉ PARA PROFESSORES: O ESTUDO COMO DIMENSÃO CONSTITUTIVA DO OFÍCIO DE PROFESSOR

para o período de observação dos estágios, decompõem ela mesma o seu fazer, para mostrá-lo: há ali, em sala de aula, uma espécie de ensaio permanente. O uso dos materiais e a preparação da aula é alvo de conversas nas quais são destacadas aquilo que é próprio do escolar, e que consideramos fundamental para estudar e praticar o ofício.

\section{3. "Considerações em torno do ato de estudan"}

A noção de ensaio permanente, para falar deste momento de observação e do papel exercido pela professora coorientadora, tem sua inspiração em um filme de Pedro Costa intitulado Ne change rien ${ }^{11}$. O reconhecido cineasta português acompanha e filma a atriz e cantora francesa Jeane Balibar por cinco anos em ensaios, gravações, alguns concertos, aulas de canto etc. Parte fundamental do documentário se passa num estúdio em Tokyo com ela e seus músicos. Há uma tentativa, por parte do cineasta, de captar se o trabalho de Jeane com os músicos se assemelha a ideia que ele tem de cinema, como um exercício ascético, paciente e de trabalho diário. A película está toda baseada na repetição: assistimos a cenas e mais cenas de preparação e de repetição dos movimentos do corpo, da voz e dos embates com o som dos instrumentos. Introduz, de certa forma, o espectador na disciplina e num certo tédio da criação musical, que também pode ser entendido como um elemento indispensável à criação.

Como na formação inicial, os estudantes são submetidos a disciplina e ao tédio da composição de uma aula, no sentido da preparação que a envolve e de uma ritualidade com a qual se deparam em sala de aula e para a qual deveriam atentar. No texto "A lição mais bonita do mundo" ${ }^{12}$, Lopez aproxima a figura do artesão da do professor e a distancia, em certo sentido, da figura do artista. Dado que ao artista é reivindicada uma certa originalidade, autoria, criatividade e iniciativa, por outro lado, o professor apresenta uma "modéstia constitutiva", típica do trabalho artesanal e cujos procedimentos não estão subordinados à eficácia e à eficiência». Acima de tudo os desenvolve de «uma maneira quase ritual» e, diríamos, aprecia as coisas e o modo de poder fazê-las, com atenção e cuidado. O professor nunca será o autor ou o inventor de quem fala, mas o único a fazer falar este autor, fazê-lo brilhar. Como diz Lopez, ele "trabalha atento e minucioso para criar um objeto muito particular: a lição" (Larrosa, 2018a, p. 422) o que, em nosso caso, chamaríamos de aula.

Numa das passagens da obra de Larrosa, Esperando não se sabe o quê, numa seção nomeada "De um ofício como outro qualquer», o autor cita um documentário sobre a obra de um famoso músico brasileiro falecido, Tom Jobim e diz que o que

11. Ne changes rien. Dir.: Pedro Costa, 2009, Portugal/França, 143min.

12. Este texto trata-se de uma carta do professor Maximiliano Valerio Lopez ao professor Jorge Larrosa. Está presente na obra de Larrosa (2018a, pp. 421-423). 

DO OFÍCIO DE PROFESSOR

lhe chamou a atenção foi o depoimento de sua irmã e de sua primeira esposa, que enfatizava as muitas horas de estudo de Tom a "praticar escalas, a experimentar harmonias, a estudar outros compositores»(2018a, p. 423), cotidiana e repetidamente para, ao final, apresentar composições que pareciam ter sido saídas espontânea e naturalmente de seu talento. O que queremos destacar com estas referências é a preparação como elemento do que estamos definindo como estudo, bem como seus gestos constitutivos.

Parte desta preparação está relacionada aos artefatos do universo docente, os quais compreenderiam o que podemos chamar de uma tecnologia escolar. ${ }^{13}$ Entre 2017 e 2018 um grupo de professores do Colégio de Aplicação da Universidade Federal de Santa Catarina reuniram-se com a proposta de desenvolverem «exercícios de pensamento" acerca do ofício de professor. ${ }^{14} \mathrm{O}$ objetivo era o de, através da observação e de registros materiais, identificar o que compunha o ofício do professor, quais os gestos, os materiais, os espaços enfim, certa atmosfera que envolve o trabalho docente e que, de certa maneira, o define.

A primeira constatação é a de que havia um dentro e um fora da sala de aula e que em ambos os lugares o professor encontrava-se rodeado por artefatos. Uma das professoras filmou as mesas dos colegas e foi possível identificar ali vários elementos comuns, como os calendários e grampeadores. A presença destes e outros objetos nos fez concebê-las como mesas de montagem, uma preparação para a sala de aula. Outra filmagem deu a ver o interior das bolsas e mochilas docentes e a infinidade de materiais relacionados ao ofício que, ao serem mostrados, se desdobravam em explicações sobre seus usos. Como disse a colega: «Um professor carrega o mundo». Ao adentrar na sala de aula, outro participante realiza fotos do quadro-negro; a cada disciplina, um quadro se mostra, um registro se faz. E além disso, como diriam Masschelein e Simons: "A lousa não é apenas uma superfície em que a matéria aparece na forma escrita. Muitas vezes a lousa mantém o professor no chão". (2015, p. 55).

Neste sentido, entendemos que os professores em formação devem -mais do que realizar entrevistas com os docentes- observar, registrar e pensar a respeito dos artefatos e, por conseguinte, das tecnologias envolvidas neste saber fazer. O que se quer é que estes estudantes possam estudar também os artefatos e as tecnologias escolares no sentido de ampliar o olhar sobre estas materialidades. Dessa forma

13. Entendemos tecnologia escolar segundo a concepção de Masschelein e Simons (2015), como os artefatos simples como o quadro-negro, o giz, a carteira, a cadeira, o lápis, bem como os métodos tais como, o ditado, as tarefas, os lembretes, os exames etc.

14. Tal exercício faria parte de um conjunto de atividades denominadas de "Elogio da Escola", do qual somos coordenadoras, cujo tema em 2018 foi «Elogio da Escola: sobre o ofício do professor». Tal atividade foi exposta também na instituição escolar, sob o nome de «Elogio ao ofício do professor: uma exposição". 
KAREN CHRISTINE RECHIA Y CAROLINE JAQUES CUBAS UMA SKHOLÉ PARA PROFESSORES: O ESTUDO COMO DIMENSÃO CONSTITUTIVA DO OFÍCIO DE PROFESSOR

espera-se que algumas dicotomias, como tradição versus inovação, não façam parte de seu repertório. Como expressa Larrosa e Rechia,

Acredito que para compreender a um professor é preciso perguntar-se quais artefatos usa e quais não usa, porque o faz e o que mobiliza com esses artefatos. Que é o que dar a ver, escutar, ler, escrever, pensar, e que é o que eles invisibilizam ou silenciam. Todavia, os artefatos do professor muitas vezes se tornam invisíveis, sobretudo desde perspectivas que entendem o ofício de professor como intercâmbio intelectual, mas desprovido de materialidade (2018b, p. 61).

Portanto, ao contrário de esvaziar o trabalho do professor de sua materialidade, que esta compreensão possa fortalecer o lugar dos saberes docentes. Ainda Larrosa e Rechia ao definir certas características próprias do ato de estudar, diz que «O estudo requer, também, atenção, humildade, repetição, paciência, certa obediência inclusive, um certo deixar-se mandar pela matéria mesma de estudo.» (2018b, p. 158). Em 1968, em seu exílio no Chile, o grande educador brasileiro Paulo Freire escreveu um texto intitulado Considerações em torno do ato de estudar, cujo conteúdo diz respeito a certas prescrições para quem quer estudar um texto. O que o ato de estudar requer de quem estuda: "Que o ato de estudar, no fundo é uma atitude frente ao mundo. [...] Que o ato de estudar demanda humildade.» E por fim, que "estudar não é um ato de consumir ideias, mas de criá-las e recriá-las» (Freire, 1981, s/p). ${ }^{15}$ De certa forma tem sido nossa tentativa na formação inicial fazer com que os estagiários sejam estudantes e se entreguem ao estudo. Que um professor não é um pesquisador, nem um autor, necessariamente, mas um estudioso, que o estudo não produz resultados, nem obras, que ele não trabalha para um mundo produtivo, e talvez por isso, diferente da aprendizagem, o estudo nunca se acabe.

\section{Para finalizar}

"Olhar, ver e reparar são maneiras distintas de usar o órgão da vista», nos diz José Saramago, em "História do Cerco de Lisboa». (Saramago, 1998, p. 166). Pode-se olhar sem ver, ver e não dar por isso ou reparar, o que leva à uma sorte de visão plena, apenas quando a atenção se concentra em um ponto determinado. Não cremos, certamente, na plenitude de nosso olhar. É preciso, todavia, assumir que nossa condição de professoras que formam professores impele-nos a uma observação atenta dos modos e maneiras de ser professor. Essa observação, por sua vez, é possibilitada por nossa presença na escola. O estágio, esta etapa fundamental da formação docente inicial, constitui-se em um tempo e espaço de atenção à escola. Tem por assunto o ofício do professor e por matéria os elementos que constituem este ofício. Nossa tarefa, é, cremos, expor estes elementos e transformá-los em matéria de estudo.

15. Escrito em 1968, no Chile, este texto serviu de introdução à relação bibliográfica que foi proposta aos participantes de um seminário nacional sobre educação e reforma agrária. 

DO OFÍCIO DE PROFESSOR

Ainda que tenha uma dimensão inegavelmente profissionalizante na estrutura universitária vigente, o estágio tem, igualmente, um caráter eminentemente escolar na medida em que, por meio de determinados arranjos e operações, promove uma experiência escolar, conforme apresentada por Masschelein e Simons. Os autores recorrem a Michel Serres para tratar desta experiência escolar como a "de alguém que aprende a nadar estando na condição de não ser capaz (completamente) ainda de nadar» (Masschelein e Simons, 2015, p. 56). Aproximam a experiência escolar como a experiência de se estar no meio de coisas. Como quando ainda não se domina determinada habilidade, mas, ao mesmo tempo, a condição de desconhecê-la já é inexistente. É um ínterim. Se o que está em jogo na experiência escolar, conforme indicam, refere-se ao preparo e a prática, podemos pensar a formação docente inicial como um arranjo de espaço, tempo e matéria que abre a possibilidade para uma experiência. A experiência do estágio, em si, não torna alguém professor. Por outro lado, na medida em que nela algo aconteça, não se sai dela da mesma forma como quando se iniciou. Como dizem Masschelein e Simons, "as experiências escolares remetem a experiência [...] de um curso de vida interrompido em que novos cursos se tornem possíveis» (Masschelein e Simons, 2015, p. 55).

Nosso papel é, assim, criar condições para que algo -relativo ao ofício de professor- aconteça. Neste texto, nossa intenção foi atentar à incontornável (e talvez anacrônica) presença do estudo, de um hábito estudioso como elemento que forma e dá forma a este ofício. No estágio, nesta skbolé para professores, cabe-nos chamar a atenção para os elementos constitutivos da profissão. Tendemos a acreditar fortemente, a partir deste diálogo e daquilo que temos acompanhado, que estes elementos transcendem os conteúdos e metodologias. Obviamente são aspectos relevantes, assim como as condições sociais de nossa profissão, mas existe algo mais. Algo quase que intangível. Que compõem o romance de formação de cada um e que se anuncia em eventos entrevistos, em rápidos aperçues. Trabalhar com a formação docente inicial trata fundamentalmente de dar materialidade a eles. De retirá-los do âmbito individual e torná-los públicos. Trata, por fim, de dar a ver as ferramentas do ofício para que os alunos possam, cada qual à sua maneira, ser os professores que serão.

\section{REFERÊNCIAS BIBLIOGRÁFICAS}

Agamben, G. (2018). Autorretrato em el estudio. Buenos Aires: Adriana Hidalga editora.

Agamben, G. (2015). Meios sem fim: notas sobre a política. Belo Horizonte: Autêntica.

Agamben, G. (2014). Nudez. Belo Horizonte: Autêntica.

Biesta, G. (2017). Para além da aprendizagem: educação democrática para um futuro bumano. Belo Horizonte: Autêntica.

Bittencourt, C. (2011). Abordagens históricas sobre a História escolar. Porto Alegre. Educação E Realidade, 36(1), 83-104.

Camus, A. (2018). O avesso e o direito. Record: Rio de Janeiro. 
KAREN CHRISTINE RECHIA Y CAROLINE JAQUES CUBAS UMA SKHOLÉ PARA PROFESSORES: O ESTUDO COMO DIMENSÃO CONSTITUTIVA DO OFÍCIO DE PROFESSOR

Cornelissen, G. (2011). El papel público de la enseñanza. En M. Simons, J. Masschelein, J. e J, Larrosa (Eds.), Jacques Rancière: la educación pública y la domesticación de la democracia (pp. 41-73). Buenos Aires: Miño y Dávila Editores.

Crary, J. (2016). 24/7: capitalismo tardio e os fins do sono. Trad. Joaquim Toledo, Jr. São Paulo: Ubu.

Cubas, C. J. e Rechia, K. C. (2017). O que faz uma aula? Didática e formação docente inicial. Disponível em: http://38reuniao.anped.org.br/sites/default/files/resources/programacao/ trabalho_38anped_2017_GT04_737.pdf. (Acesso em 22/07/2019).

Deleuze, G. (2006). Proust e os signos. Rio de Janeiro: Forense Universitária.

Fernández Liria, C., García Fernández, O. e Galindo Ferrández, E. (2017). Escuela o barbarie: entre el neoloiberalismo salvaje y el delirio de la izquierda. Madrid: Akal.

Flusser, V. (1994). Los gestos: fenomenologia y comunicación. Barcelona: Editorial Herder.

Flusser, V. (s/d). Ter Tempo. Disponível em www.flusserbrasil.com. (Acessado em 22/07/2019).

Freire, P. (2015). Pedagogia da Autonomia: saberes necessários à prática educativa. Rio de Janeiro: Paz e Terra.

Freire, P. (1981), Considerações em torno do ato de estudar. In: Ação Cultural para a Liberdade. Rio de Janeiro: Paz e Terra.

Genette, G. (1966). Frontières du récit. Communications, 8, 152-163. Disponível em: https:// www.persee.fr/issue/comm_0588-8018_1966_num_8_1 (Acesso em 22/07/2019).

Gumbrecht, H. (2010). Produção de Presença: o que o sentido não consegue transmitir. Rio de Janeiro: Contraponto.

Julia, D. (2001). A cultura escolar como objeto histórico. Revista Brasileira de História da Educação, 1, 9-43.

Kosellek, R., Meier, C., Günther, H. y Engels, O. (2013). O conceito de História. Tradução de René Gertz. Autêntica: Belo Horizonte.

Larrosa, J. (Org.) (2017). Elogio da Escola. Belo Horizonte: Autêntica.

Larrosa, J. (2018a). Esperando não se sabe o quê: sobre o ofício de professor. Trad.: Cristina Antunes. $1^{\mathrm{a}}$. ed. Belo Horizonte: Autêntica.

Larrosa, J. e Rechia, K. (2018b). P de Professor. São Carlos: Pedro \& João Editores.

Masschelein, J. e Simons, M. (2014). A pedagogia, a democracia, a escola. Belo Horizonte: Autêntica.

Masschelein, J. e Simons, M. (2015). Em defesa da Escola: uma questão pública. Belo Horizonte: Autêntica.

Pennac, D. (2008). Diário de Escola. São Paulo: Rocco.

Rancière, J. (2002). O mestre ignorante: cinco ensaios sobre a emancipação intelectual. Belo Horizonte: Autêntica.

Romilly, J. de. (1991). Ecrits sur l'enseignement. Paris: Editions de Fallois.

Rüsen, J. (2006). Didática da História: passado, presente e perspectivas a partir do caso alemão. Práxis Educativa, 1(2), 7-16.

Saramago, J. (1998). História do Cerco de Lisboa. São Paulo: Companhia das Letras.

Tardif, M. (2018). Saberes docentes e formação profissional. Petrópolis: Vozes. 